Original
article

\title{
Pleural effusions in patients with AIDS
}

\author{
Robert F Miller, Sarah J Howling, Andrew J Reid, Penny J Shaw
}

Objective: To describe the range of pathology causing pleural effusions in HIV infected patients with acute respiratory episodes and to attempt to identify whether any associated radiological abnormalities enabled aetiological discrimination.

Methods: Prospective study of chest radiographs of 58 consecutive HIV infected patients with pleural effusion and their microbiological, cytological, and histopathological diagnoses.

Results: A specific diagnosis was made in all cases. Diagnoses were Kaposi's sarcoma, 19 patients; parapneumonic effusion, 16 patients; tuberculosis, eight patients; Pneumocystis carinii pneumonia, six patients; lymphoma, four patients; pulmonary embolus, two patients; and heart failure, aspergillus/leishmaniasis, and Cryptococcus neoformans, one case each. Most effusions (50/ 58) were small. Bilateral effusions were commoner in Kaposi's sarcoma (12/19) and lymphoma (3/4) than in parapneumonic effusion (3/16). Concomitant interstitial parenchymal shadowing did not aid discrimination. A combination of bilateral effusions, focal air space consolidation, intrapulmonary nodules, and/or hilar lymphadenopathy suggests Kaposi's sarcoma. Unilateral effusion with focal air space consolidation suggests parapneumonic effusion if intrapulmonary nodules are absent: if miliary nodules and/or mediastinal lymphadenopathy are detected, this suggests tuberculosis.

Conclusions: A wide variety of infectious and malignant conditions cause pleural effusions in HIV infected patients, the most common cause in this group was Kaposi's sarcoma. The presence of additional radiological abnormalities such as focal air space consolidation, intrapulmonary nodules, and mediastinal lymphadenopathy aids aetiological discrimination.

(Sex Transm Inf 2000;76:122-125)

Keywords: pleural effusion; Kaposi's sarcoma; bacterial pneumonia; chest radiograph

\section{Introduction}

Up to $70 \%$ of patients infected with the human immunodeficiency virus (HIV) will have an episode of pulmonary disease at some time during the course of their HIV disease. ${ }^{1}$ Pulmonary disease is caused predominantly by opportunistic infections, notably Pneumocystis carinii pneumonia with approximately one third of all respiratory episodes being caused by bacterial pneumonia. ${ }^{23}$ Non-infectious causes, such as Kaposi's sarcoma and non-Hodgkin's lymphoma, account for between $10 \%$ and $15 \%$ of all pulmonary disease. ${ }^{23}$

The radiological features of pulmonary disease in HIV infected patients have been described previously. ${ }^{4-6}$ Many of the radiological abnormalities are non-specific. However, certain patterns of involvement occur more commonly with specific diseases - for example, lobar or segmental consolidation with pyogenic bacterial infection and bilateral diffuse interstitial infiltrates with $P$ carinii pneumonia. $^{7-9}$ Pleural effusions have been described in immunosuppressed HIV positive patients with a wide range of pulmonary infections and malignancies, ${ }^{5-17}$ and also with non-HIV associated disease processes including cardiac, renal, and hepatic failure, ${ }^{14}{ }^{17}$ and bronchial carcinoma. ${ }^{18}$

The purpose of this study was, firstly, to describe the range of pathology causing pleural effusion in HIV infected patients presenting to a specialist unit for HIV/AIDS in London and, secondly, to attempt to identify whether any associated radiological abnormalities enabled aetiological discrimination.

\section{Methods}

We prospectively studied consecutive adult HIV infected patients presenting to the outpatient clinic, accident and emergency department, or to local general practitioners with acute respiratory symptoms and chest radiographs showing a pleural effusion, all of whom were admitted to the specialist HIV/AIDS inpatient unit at University College London Hospitals from July 1996 through to June 1998.

There were 58 patients in the study (aged 23-59 years, median age 37.5 years) 49 of whom were male. Forty three of the male patients were white of whom 40 were homosexual, two were injection drug users, and one was heterosexual, as were the four Africans, two of whom were male. The nine women (five Africans and four white women) were heterosexual. As a group, the patients were profoundly immunosuppressed with a median CD4 lymphocyte count of 40 cells $\times 10^{6} / 1$ (range $0-680$ cells $\times 10^{6} / 1$, normal range 250 1200 cells $\left.\times 10^{6} / 1\right)$. All but four patients had CD4 lymphocyte counts of 250 cells $\times 10^{6} / 1$. Twenty two patients (38\%) were receiving treatment with highly active antiretroviral therapy (HAART); in these patients their CD4+ lymphocyte counts were recorded while being treated. Most patients were receiving co-trimoxazole as prophylaxis against $P$ carinii pneumonia. There was no history of previous respiratory disease in $48(83 \%)$ patients. In the remaining patients seven had $P$ carinii pneumonia, two had Mycobacterium tuberculosis and one bacterial pneumonia. During the study there were 1032 admissions to the HIV/AIDS unit, 
Table 1 Characteristics of pleural effusions

\begin{tabular}{|c|c|c|c|c|c|c|}
\hline \multirow[b]{2}{*}{ Diagnosis } & \multicolumn{4}{|l|}{ Size } & \multicolumn{2}{|l|}{ Type } \\
\hline & Small & Moderate & Large & Massive & Unilateral & Bilateral \\
\hline \multicolumn{7}{|l|}{ Pulmonary Kaposi's sarcoma } \\
\hline $\begin{array}{l}(\mathrm{n}=19) \\
\text { Parapneumonic† effusion }\end{array}$ & 16 & 1 & 2 & 0 & 7 & 12 \\
\hline$(\mathrm{n}=16)$ & 14 & 1 & 1 & 0 & 13 & 3 \\
\hline Tuberculosis $(n=8)$ & 7 & 1 & 0 & 0 & 6 & 2 \\
\hline$P$ carinii pneumonia $\ddagger(\mathrm{n}=6)$ & 6 & 0 & 0 & 0 & 3 & 3 \\
\hline Lymphoma $(n=4)$ & 3 & 1 & 0 & 0 & 1 & 3 \\
\hline Pulmonary embolism $\mathbb{S}(n=2)$ & 2 & 0 & 0 & 0 & 1 & 1 \\
\hline Heart failure $(n=1)$ & 1 & 0 & 0 & 0 & 0 & 1 \\
\hline Aspergillus/leishmania $(n=1)$ & 1 & 0 & 0 & 0 & 1 & 0 \\
\hline Cryptococcus neoformans $(\mathrm{n}=1)$ & 0 & 1 & 0 & 0 & 1 & 0 \\
\hline Total & 50 & 5 & 3 & 0 & 33 & 25 \\
\hline
\end{tabular}

*Three also had bacterial bronchitis, two had $P$ carinii pneumonia and one a body cavity lymphoma.

†One also had liver failure.

¥Two also had heart failure.

SOne also had $P$ carinii pneumonia.

and of these 205 admissions were with respiratory disease.

During their admission the chest radiographs of the 58 patients were reviewed by two radiologists (SJH and PJS) at the same time who were blinded to the clinical diagnosis and knew only that all patients were infected with HIV-1. The size and location of the pleural effusions were noted on a chest radiograph and were designated small if the costophrenic angle was obliterated, moderate if the lower zone was completely opaque, large if the lower and middle zones were opaque, and massive if all three zones were opaque. ${ }^{14}$ In addition, the presence or absence of specific parenchymal abnormalities including air space, interstitial and ground glass shadowing, discrete nodules (and their number and size), and lymphadenopathy were recorded prospectively, using a proforma. Air space and interstitial shadowing were categorised as focal or generalised and mild (involving less than one third of a lung) or severe (involving more than one third of one or both lungs). Nodules were described by size $->1 \mathrm{~cm}$ diameter, $=1 \mathrm{~cm}$, or miliary, and by number, $=10$ or $<10$. Agreement was reached by the two radiologists on the radiographic abnormalities present in each patient.
The final diagnosis made by microbiological and cytological examination of pleural fluid (11 patients), spontaneously expectorated sputum (three patients), bronchoalveolar lavage fluid (14 patients), and blood (two patients) was noted. The specific tests used have been described previously. ${ }^{19}$ Parapneumonic effusions (16 patients) were diagnosed if they occurred concurrently with a bacterial pneumonia, diagnosed as previously described. ${ }^{3} \mathrm{~A}$ specific pathogen was identified in four patients-Staphylococcus aureus in two patients, Haemophilus influenzae in one patient, and Pseudomonas aeruginosa in one patient. Where no pathogen was identified (12 patients) a clinical and radiological response to broad spectrum antibiotics in conventional doses was used. ${ }^{3}$ Streptococcal antigen detection in pleural fluid was not used to identify recent infection with Streptococcus pneumoniae. A diagnosis of Kaposi's sarcoma made at bronchoscopy (19 patients) was on the basis of visualisation of typical lesions as previously described..$^{20}$ Pulmonary embolism (two patients) was diagnosed by computed tomograph pulmonary angiography. Three patients died during their admission. Necropsy was performed in two and confirmed the antemortem diagnosis; permission was refused in the third patient. These clinical data were then correlated with the results of the radiographic analysis.

Statistical analysis was performed by applying the $\chi^{2}$ test with Yates's correction to compare qualitative variables. A $p$ value of less than 0.05 was considered significant.

\section{Results}

The 58 patients with pleural effusions accounted for $5.6 \%$ of all admissions and $28 \%$ of all respiratory admissions during the study period. A specific diagnosis was made in all cases (table 1). Of 34 patients admitted during the study with pulmonary Kaposi's sarcoma 19 $(56 \%)$ had pleural effusion and of 55 patients admitted with $P$ carinii pneumonia six $(11 \%)$ had an effusion (table 1 ). There was no corre-

Table 2 Additional radiological features

\begin{tabular}{|c|c|c|c|c|c|c|c|c|c|}
\hline \multirow[b]{2}{*}{ Diagnosis } & \multicolumn{4}{|l|}{ Parenchymal } & \multicolumn{3}{|c|}{ Nodules } & \multicolumn{2}{|c|}{ Lymphadenopathy } \\
\hline & Interstitial & & Air space & & $>1 \mathrm{~cm}$ & $<1 \mathrm{~cm}$ & Miliary & Hilar & Mediastinal \\
\hline Pulmonary Kaposi's sarcoma $(n=19)$ & $\begin{array}{l}\text { generalised severe } \\
\text { focal mild } \\
\text { focal severe }\end{array}$ & $\begin{array}{l}7 \\
4 \\
2\end{array}$ & $\begin{array}{l}\text { focal mild } \\
\text { focal severe } \\
\text { generalised mild } \\
\text { generalised severe }\end{array}$ & $\begin{array}{r}12 \\
2 \\
1 \\
1\end{array}$ & 6 & 5 & 0 & 7 & 1 \\
\hline Parapneumonic $\dagger$ effusion $(n=16)$ & $\begin{array}{l}\text { generalised mild } \\
\text { generalised severe }\end{array}$ & $\begin{array}{l}8 \\
3\end{array}$ & $\begin{array}{l}\text { focal mild } \\
\text { focal severe }\end{array}$ & $\begin{array}{l}6 \\
5\end{array}$ & 0 & 1 & 0 & 0 & 0 \\
\hline Tuberculosis $(n=8)$ & $\begin{array}{l}\text { generalised mild } \\
\text { generalised severe }\end{array}$ & $\begin{array}{l}2 \\
2\end{array}$ & focal mild & 3 & 0 & 1 & 4 & 3 & 5 \\
\hline$P$ carinii pneumonia $\ddagger(\mathrm{n}=6)$ & $\begin{array}{l}\text { generalised severe } \\
\text { generalised mild }\end{array}$ & $\begin{array}{l}3 \\
1\end{array}$ & $\begin{array}{l}\text { focal mild } \\
\text { generalised mild }\end{array}$ & $\begin{array}{l}1 \\
1\end{array}$ & 0 & 0 & 0 & 0 & 0 \\
\hline Lymphoma $(n=4)$ & $\begin{array}{l}\text { focal mild } \\
\text { focal severe }\end{array}$ & $\begin{array}{l}1 \\
2\end{array}$ & focal mild & 2 & 0 & 0 & 0 & 0 & 1 \\
\hline Pulmonary embolism $\sqrt{ }(\mathrm{n}=2)$ & - & & $\begin{array}{l}\text { focal mild } \\
\text { focal severe }\end{array}$ & $\begin{array}{l}1 \\
1\end{array}$ & 0 & 0 & 0 & 0 & 0 \\
\hline Heart failure $(n=1)$ & focal mild & 1 & - & & 0 & 0 & 0 & 0 & 0 \\
\hline Aspergillus/leishmania $(n=1)$ & - & & focal mild & 1 & 0 & 0 & 0 & 0 & 0 \\
\hline Cryptococcus neoformans $(\mathrm{n}=1)$ & - & & focal mild & 1 & 0 & 0 & 0 & 0 & 0 \\
\hline Total & & & & & 6 & 7 & 4 & 10 & 7 \\
\hline
\end{tabular}

*Three also had bacterial bronchitis, two had $P$ carinii pneumonia, and one a body cavity lymphoma.

tOne also had liver failure.

$¥$ Two also had heart failure.

SOne also had $P$ carinii pneumonia. 
lation between the patients' diagnoses and their CD4 lymphocyte counts (data not shown).

Most effusions (50 cases) were small (table 1). Bilateral effusions were commoner in Kaposi's sarcoma (12/19) and lymphoma (3/4) than in those that were parapneumonic $(3 / 16)$ (Yates's corrected $\chi^{2}$ test $=5.30 ; 1 \mathrm{df} ; \mathrm{p}=$ 0.002 ) but were also seen in $P$ carinii pneumonia (3/6) and in other causes (table 1$)$. Mediastinal lymphadenopathy was seen most frequently in tuberculosis (5/8) but also in Kaposi's sarcoma and lymphoma (one case each) (table 2) Intrapulmonary nodules were seen in 17 patients. Miliary nodules (four patients) were seen only in tuberculosis; all had more than 10 nodules (table 2). Nodules more than $1 \mathrm{~cm}$ in diameter and less than 10 in number were seen only in Kaposi's sarcoma (six patients). Nodules of $1 \mathrm{~cm}$ in diameter and less than 10 in number were also more often the result of Kaposi's sarcoma (five patients) and were also seen in parapneumonic effusion and tuberculosis (one patient each). Concomitant interstitial parenchymal shadowing did not aid discrimination between causes of pleural effusion (table 2). Focal air space consolidation was commoner with Kaposi's sarcoma (73.6\%) and parapneumonic effusion (68\%) in contrast with tuberculosis $(37.5 \%)$ but was also seen with other causes of effusion. Generalised ground glass shadowing was seen in only one patient, who had $P$ carinii pneumonia.

\section{Discussion}

This study firstly sought to describe the range of pathology causing pleural effusion in consecutive hospitalised HIV infected patients with acute respiratory episodes. We found a wide range of infective and non-infective processes, including Kaposi's sarcoma in 34.5\%, parapneumonic effusion in $29 \%$, and tuberculosis in $14.5 \%$. Several studies of respiratory disease in HIV infected patients have reported a lower incidence of Kaposi's sarcoma. In one retrospective study from South Carolina, USA, pleural effusions occurred in 59 of 222 patients with AIDS (27\%) hospitalised over a 5 year period. ${ }^{14}$ Parapneumonic effusion occurred in 18 patients $(31 \%), P$ carinii pneumonia in nine patients (15\%), and $M$ tuberculosis in five patients $(8 \%)$; hypoalbuminaemia secondary to liver or renal disease, or to advanced HIV disease, accounted for 19\% of effusions (11 patients). Only one patient had effusion due to Kaposi's sarcoma. ${ }^{14}$ Another retrospective study from Austria found pleural effusion occurred in 28 of 389 HIV infected patients $(7.2 \%)$ over a 3 year period. Parapneumonic effusion in nine patients (33\%), $M$ tuberculosis in six $(21.5 \%)$, and non-Hodgkin's lymphoma in four $(14 \%)$ were the most frequent causes. ${ }^{15}$ $P$ carinii pneumonia and Kaposi's sarcoma were responsible for two cases each. In contrast with these two studies, another study from Paris reported 37 cases of pleural effusion in patients with AIDS where $21(57 \%)$ were due to Kaposi's sarcoma and $43 \%$ were due to infection. ${ }^{16}$

Differences in the relative frequencies of the different aetiologies in these studies and our own may be explained by several factors. Bacterial infections, including pneumonia, occur with greater frequency in HIV infected patients whose risk factor is intravenous drug use, compared with those who acquire HIV via sex or blood products. ${ }^{21}$ In addition, Kaposi's sarcoma occurs more commonly in homosexual males than in drug users. Our study population consisted largely of homosexual males as did the study from Paris. ${ }^{16}$ Several of these studies were reported from early in the AIDS pandemic before combination antiretroviral therapy was available and before widespread use of prophylaxis against $P$ carinii pneumonia. ${ }^{1416}$ The widespread availability and use of combination antiretroviral therapy and anti- $P$ carinii prophylaxis has resulted in marked reductions in frequency of many opportunistic infections. ${ }^{22}{ }^{23}$ In our study most patients were taking co-trimoxazole as prophylaxis and $22(38 \%)$ were taking HAART.

Most effusions, $50 / 58(86 \%)$ in our study, were small and so we could not use size alone to provide discriminatory information for diagnosis. However, small bilateral effusions were more often the result of Kaposi's sarcoma (12/ $19)$ and lymphoma (3/4) than parapneumonic effusion (3/16), but were also seen with $P$ carinii pneumonia (two of the three patients also had heart failure) and tuberculosis. This is similar to the study from Paris where 20/21 with Kaposi's sarcoma and 1/16 with infective effusions had bilateral effusions. ${ }^{16}$ However, in 15 of those with Kaposi's sarcoma the effusions were moderate or large, whereas 15 of 16 with infection had small or medium sized effusions. ${ }^{16}$ Unilateral small effusions in our study occurred most frequently with parapneumonic effusion and tuberculosis. Similar data were found in the study from South Carolina, where $78 \%$ of all effusions were small and were found in a variety of conditions. ${ }^{14}$ Data were not given for all the patients but six of the nine with $P$ carinii pneumonia had unilateral effusion.

The second aim of this study was to attempt to identify if any associated radiological abnormalities enabled discrimination between diagnoses to be made. While no specific parenchymal abnormality was pathognomonic for any particular condition, a diagnosis of Kaposi's sarcoma was suggested by the combination of bilateral effusions, even when small, with focal air space consolidation, intrapulmonary nodules, and/or hilar lymphadenopathy. In contrast, unilateral effusions with focal air space consolidation in the absence of nodules suggests that the effusion is parapneumonic in origin; if miliary nodules are present, or lymphadenopathy and unilateral effusion a diagnosis of tuberculosis is suggested.

In conclusion, in this group of HIV infected patients, pleural effusion was associated with a variety of infective and malignant processes. Most effusions were small in size but bilateral effusion should suggest Kaposi's sarcoma or lymphoma. The presence of additional radiological abnormalities such as focal air space consolidation, intrapulmonary nodules, and 
mediastinal lymphadenopathy aids aetiological discrimination.

Sources of funding: nil.

Conflicts of interest: nil.

Contributors: All authors contributed to the design of the study, to data collection, and to writing drafts of the manuscript. RFM put forward the original research proposal, collated the radiological and clinical data and wrote the first and final drafts of the manuscript; SJH and PJS prospectively reported the ches radiographs and helped revise drafts of the manuscript; AJR collected the clinical data and helped revise drafts of the manuscript.

1 Miller RF. HIV-associated respiratory diseases. Lancet 1996;348:307-12.

2 Polsky B, Gold JW, Whimbey E, et al. Bacterial pneumonia in patients with the acquired immunodeficiency syndrome. Ann Intern Med 1986;104:38-41.

3 Pitkin AD, Grant AD, Foley NM, et al. Changing patterns of respiratory disease in HIV positive patients in a referral respiratory disease in HIV positive patients in a referral 1990-1. Thorax 1993;48:204-7.

4 Cohen BA, Pomeranz S, Rabinowitz JG, et al. Pulmonary complications of AIDS: radiologic features. Am $\mathcal{F}$ Radio

5 Suster B, Akerman M, Orenstein M, et al. Pulmonary manifestations of AIDS: review of 106 episodes. Radiology 1986 161:87-93.

6 Kuhlman JE. Imaging pulmonary disease in AIDS: state of the art. Eur Radiol 1999;9:395-408.

7 Sider L, Gabriel H, Curry DR, et al. Pattern recognition of the pulmonary manifestations of AIDS on CT scans. Radiographics 1993;13:771-84.

8 Amorosa JK, Niahass RG, Nosher JL, et al. Radiologic distinction of pyogenic pulmonary infection from Pneumotinction of pyogenic pulmonary infection from Pneumocysitis carini1 pne

9 Amin Z, Miller RF, Shaw PJ. Lobar or segmental consolidation on chest radiographs of patients with HIV infection. Clin Radiol 1997;52:541-5.
10 Kuhlman JE, Kavuru M, Fishman EK, et al. Pneumocystis carinii pneumonia: spectrum of parenchymal CT findings. Radiology 1990;175:711-14

11 Batungwanayo J, Taelman H, Bogaerts J, et al. Pulmonary crypotococcosis associated with HIV-1 infection in Rwanda: a retrospective study of 37 cases. AIDS 1994;8: 1271-6.

12 Eisner MD, Kaplan LD, Herndier B, et al. The pulmonary manifestations of AIDS-related non-Hodgkin's lymphoma. Chest 1996;110:729-36.

13 Miller RF, Tomlinson MC, Cottrill CP, et al. Bronchopulmonary Kaposi's sarcoma in patients with AIDS. Thorax 1992;47:721-5.

14 Joseph J, Strange C, Sahn S. Pleural effusions in hospitalized patients with AIDS. Ann Intern Med 1993;118:856-9.

15 Armbruster C, Schalleschak J, Vetter N, et al. Pleural effusions in human immunodeficiency virus-infected patients. Acta Cytol 1995;39:698-700

16 Allier I, Cadranel J, Parquin F, et al. Pleuresies chez les malades infectes par le VIH. Presse Med 1991;20:1931-4.

17 Trejo O, Giron JA, Perez-Guzman E, et al. Pleural effusion in patients infected with the human immunodeficiency virus. Eur 7 Clin Microbiol Infect Dis 1997;16:807-15.

18 White CS, Haramati LB, Elder KH, et al. Carcinoma in the lung in HIV-positive patients: findings on chest radiographs lung in HIV-positive patients: findings on chest

19 Miller RF, Kocjan G, Buckland J, et al. Sputum induction for the diagnosis of respiratory disease in HIV positive for the diagnosis of respiratory

20 Hughes-Davies L, Kocjan G, Spittle MF, et al. Ocult alveolar haemorrhage in bronchopulmonary Kaposi's sarcoma. $\mathcal{F}$ Clin Pathol 1992;45:536-7.

21 Selwyn PA, Feingold AR, Hartel D, et al. Increased risk of bacterial pneumonia in HIV-infected intravenous drug users without AIDS. AIDS 1998;2:267-72

22 Jacobson MA, French M. Altered natural history of AIDSrelated opportunistic infections in the era of potent combination antiretroviral therapy. AIDS 1998;12(suppl A): S157-63.

23 Jones JL Hanson DL, Dworkin MS, et al. Trends in AIDSrelated opportunistic infections among men who have sex with men and among injecting drug users, 1991-1996. F Infect Dis 1998;178:114-20. 